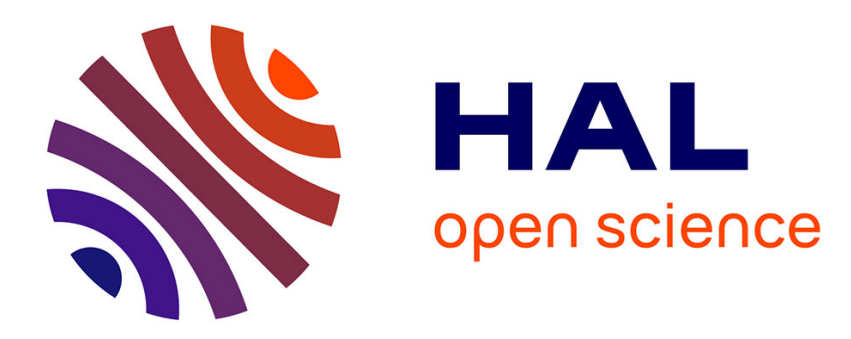

\title{
La politique religieuse de la Chine au Tibet
}

Fabienne Jagou

\section{To cite this version:}

Fabienne Jagou. La politique religieuse de la Chine au Tibet. Revue d'Etudes Comparatives Est-

Ouest, 2001, 32 (1), pp.29-54. 10.3406/receo.2001.3070 . hal-02557100

\section{HAL Id: hal-02557100 \\ https://hal.science/hal-02557100}

Submitted on 28 Apr 2020

HAL is a multi-disciplinary open access archive for the deposit and dissemination of scientific research documents, whether they are published or not. The documents may come from teaching and research institutions in France or abroad, or from public or private research centers.
L'archive ouverte pluridisciplinaire HAL, est destinée au dépôt et à la diffusion de documents scientifiques de niveau recherche, publiés ou non, émanant des établissements d'enseignement et de recherche français ou étrangers, des laboratoires publics ou privés. 


\section{La politique religieuse de la Chine au Tibet}

\section{Fabienne Jagou}

\section{Citer ce document / Cite this document :}

Jagou Fabienne. La politique religieuse de la Chine au Tibet. In: Revue d’études comparatives Est-Ouest, vol. 32, $2001, \mathrm{n}^{\circ} 1$. Politique et religion en Asie orientale. pp. 29-54;

doi : https://doi.org/10.3406/receo.2001.3070

https://www.persee.fr/doc/receo_0338-0599_2001_num_32_1_3070

Fichier pdf généré le 12/04/2018 


\title{
Résumé
}

La situation politique et religieuse tibétaine a considérablement changé depuis l'entrée de l'armée chinoise au Tibet en 1950. À partir de cette date, la Chine exerça au Tibet une politique équivalente à celle qu'elle imposa à ses habitants, notamment en matière religieuse. Compte tenu des spécificités bouddhiques du Tibet, la politique religieuse y fut menée de façon radicale. Elle attaquait les fondements de la culture tibétaine : le monastère, les moines et les maîtres réincarnés. Les monastères furent donc tour à tour détruits, rénovés et fermés. Les moines durent se séculariser, puis des ordinations furent autorisées et strictement réglementées. Les maîtres réincarnés, après avoir subi le même sort que les moines, furent récupérés par le gouvernement chinois pour l'aider à appliquer sa politique au Tibet.

\begin{abstract}
The Tibetan political and religious situation has changed considerably since the Chinese army onslaught in 1950. From then on, China has applied policies there similar to the one imposed on its own inhabitants, especially in religious matters, but in a more radical manner owing to the features of Tibetan Buddhism. This religious policy attacks Tibetan culture's very foundations : monasteries, monks and reincarnated masters. Monasteries were destroyed, renovated, then closed. Monks were secularized until ordination was authorised under tight control. The Chinese used the reincarnated masters, who had met the same fate as monks, to help them enforce their policies in Tibet.
\end{abstract}




\title{
La politique religieuse de la Chine au Tibet
}

\author{
Fabienne JAGOU *
}

\begin{abstract}
RÉSUME : La situation politique et religieuse tibétaine a considérablement changé depuis l'entrée de l'armée chinoise au Tibet en 1950. À partir de cette date, la Chine exerça au Tibet une politique équivalente à celle qu'elle imposa à ses habitants, notamment en matière religieuse. Compte tenu des spécificités bouddhiques du Tibet, la politique religieuse y fut menée de façon radicale. Elle attaquait les fondements de la culture tibétaine : le monastère, les moines et les maîtres réincarnés. Les monastères furent donc tour à tour détruits, rénovés et fermés. Les moines durent se séculariser, puis des ordinations furent autorisées et strictement réglementées. Les maîtres réincarnés, après avoir subi le même sort que les moines, furent récupérés par le gouvernement chinois pour l'aider à appliquer sa politique au Tibet.
\end{abstract}

ABSTRACT: The Tibetan political and religious situation has changed considerably since the Chinese army onslaught in 1950. From then on, China has applied policies there similar to the one imposed on its own inhabitants, especially in religious matters, but in a more radical manner owing to the features of Tibetan Buddhism. This religious policy attacks Tibetan culture's very foundations : monasteries, monks and reincarnated masters. Monasteries were destroyed, renovated, then closed. Monks were secularized until ordination was authorised under tight control. The Chinese used the reincarnated masters, who had met the same fate as monks, to help them enforce their policies in Tibet.

\section{INTRODUCTION}

Au Tibet, au début du $\mathrm{XX}^{\mathrm{e}}$ siècle, les pouvoirs politiques et religieux étaient étroitement imbriqués. Une théocratie bouddhique, dont le chef charismatique (le 13e Dalaï Lama, 1875-1933) cumulait les pouvoirs spirituel et temporel, présidait aux destinées de la nation tibétaine ${ }^{1}$. En l'absence du Dalaï Lama (chef de l'école bouddhique des dGe-lugs-pa) ou pendant sa minorité, un régent (religieux) gouvernait le pays. Il était élu par un Cabinet ministériel (créé en 1720) puis, à partir de 1875, par l'Assemblée nationale. Le gouvernement tibétain se divisait en deux branches principales, l'une chargée des affaires religieuses, l'autre des affaires civiles et militaires. La branche civile et militaire était administrée par des laïcs qui travaillaient en étroite collaboration avec des moines.

* Chargée de recherche à l'École française d'Extrême-Orient (22 avenue du Président-Wilson, 75116 Paris. E-mail : fabienne.jagou@free.fr).

1. Les maîtres appartenant à une lignée de réincarnation sont classés par ordre chronologique. Ainsi, dGe-'dun grub (1391-1474) et dGe-'dun rgya-mtsho (1476-1542) reçurent le titre de Dalaï Lama à titre posthume après qu'Altan-khan (1507-1582) l'eut attribué à bSod-nams rgya-mtsho (1543-1588), troisième maître de la lignée de réincamation, dont il louait l'érudition. 
La structure gouvernementale tibétaine administrait une organisation sociale complexe dans laquelle les relations politico-religieuses jouaient un rôle considérable. Le statut d'une terre et celui des impôts afférents à celle-ci, fixés par le gouvernement, variaient considérablement d'une région à l'autre, d'une famille aristocratique à une autre ou de la renommée du monastère bouddhique implanté sur cette terre (Carrasco, 1959, p. 86; Surkhang, 1986, p. 28-29). Les terres du Tibet, appartenant au Dalaï Lama (il pouvait les donner, les reprendre et les redistribuer à tout moment), étaient divisées en trois groupes principaux : celles du gouvernement, celles de l'aristocratie et celles du clergé. En dernier lieu, des paysans-contribuables (khral-pa, littéralement « ceux qui paient des impôts ») cultivaient l'ensemble de ces terres dont une partie plus ou moins étendue leur avait été attribuée et qu'ils pouvaient sous-louer (Goldstein, 1986, p. 85). Les revenus des uns et des autres se complétaient pour converger vers le monastère. En fait, le monastère était au centre de la vie politique, économique et religieuse tibétaine. Ainsi, les abbés des trois grands monastères dGe-lugs-pa ('Bras-spungs, dGa'-ldan et Se-ra) participaient au gouvernement, les régents étaient choisis parmi un cercle restreint de hiérarques religieux (les maîtres réincarnés), la production économique était essentiellement dirigée vers les monastères, la vie religieuse (transmission des enseignements bouddhiques, fêtes religieuses, etc.) se faisait le plus souvent dans leurs murs et étaient organisées par des moines. Les monastères formaient également des unités autonomes ayant chacune son administration, ses terres et ses protecteurs.

Le fragile équilibre qui régissait la vie de la société tibétaine dura jusqu'au milieu du $\mathrm{xx}^{\mathrm{e}}$ siècle. Depuis 1950 , année de l'invasion chinoise, le Tibet central, devenu la Région autonome du Tibet, est dirigé par le gouvernement de Pékin qui a remis en cause les fondements de la société tibétaine. Ainsi, là où hier la religion primait sur la vie politique et sociale, aujourd'hui le politique l'emporte sur le religieux. Le gouvernement chinois édicte sans cesse des lois visant à un meilleur contrôle de la vie religieuse tibétaine. Depuis 1959, année de la fuite du $14^{\mathrm{e}}$ Dalai Lama, chef spirituel et temporel du Tibet, le paysage religieux tibétain s'est considérablement modifié du fait de cette intervention politique forcée.

\section{LA LIBERTÉ DE RELIGION AU TIBET : UN STATUT PRÉCAIRE}

\subsection{PÉKIN-LHASA : UNE HISTOIRE MOUVEMENTÉE}

Le 10 octobre 1949, quand la République populaire de Chine fut proclamée, seul le peuple tibétain n'était pas encore "libéré" aux dires de Radio Pékin. Une semaine plus tard, l'Armée populaire de libération entra au Tibet et se heurta aux forces tibétaines à Chab-mdo. D'emblée, le gouvernement de Pékin chercha 
à utiliser la renommée des $14^{\mathrm{e}}$ Dalaï Lama et $10^{\mathrm{e}}$ Panchen Lama $(1938-1989)^{2}$ au profit de sa politique.

Une délégation du gouvernement tibétain, dirigée par Nga-phod Ngag-dbang 'Jigs-med (gouverneur civil et militaire de la région de Chab-mdo et ancien ministre du gouvernement tibétain), fut envoyée à Pékin pour négocier avec la .République populaire de Chine. Le 23 mai 1951, l'« Accord en dix-sept points concernant la libération pacifique du Tibet » fut signé sous la contrainte par les représentants du gouvernement tibétain. Cet accord était supposé marquer le « retour du Tibet au sein de la mère-patrie » tout en lui permettant d'exercer son droit à l'autonomie. Mais la Chine ne tarda pas à violer ces articles. Elle imposa des réformes agricoles (redistribution des terres et modification des cultures) et cessa de respecter la religion bouddhique locale. Le 26 octobre 1951, l'Armée populaire de libération chinoise entra à Lhasa. En janvier 1956, Pékin envoya quinze divisions (soit 150000 hommes) dans le Khams pour mater la rébellion. Suivront deux années de terreur dans les provinces du Khams et de l'A-mdo. À Lhasa, les réfugiés affluaient et les témoignages malheureux circulaient. La même année, la «Commission préparatoire pour la création de la Région autonome du Tibet » fut créée. Le gouvernement tibétain perdait petit à petit ses pouvoirs.

Le 10 mars 1959, le $14^{\mathrm{e}}$ Dalaï Lama quitta précipitamment le Tibet. La majorité des membres de son gouvernement et les principaux hiérarques religieux (à l'exception du $10^{e}$ Panchen Lama) prirent eux aussi le chemin de l'exil. Quelques jours plus tard, le gouvernement tibétain fut dissous par les autorités chinoises qui mirent en place un comité présidé et chargé par le $10^{e}$ Panchen Lama de préparer la création de la Région autonome du Tibet. Les provinces tibétaines du Khams et de l'A-mdo furent rattachées à la Chine. Le Khams se fondit dans les provinces chinoises du Yunnan, du Sichuan et du Gansu, alors

2. Aujourd'hui, deux généalogies sont usitées pour la lignée des Panchen Lamas. L'une débute à mKhas-grub dge-legs dpal-bzang (1385-1438), disciple de Tsong-kha-pa (1357-1419), le fondateur de l'école des dGe-lugs-pa, et l'autre à Panchen Blo-bzang chos-kyi-rgyal-mtshan (1567/ 1570-1662), qui reçut son titre de Panchen Lama en 1601 du $4^{e}$ Dalaï Lama (1617-1682). Les Tibétains utilisent plus volontiers l'énumération qui démarre avec Panchen Blo-bzang chos-kyirgyal-mtshan, tandis que les Chinois ont adopté celle qui remonte à mKhas-grub dge-legs dpalbzang. Ainsi, Blo-bzang 'phrin-las lhun-grub chos-kyi-rgyal-mtshan (1938-1989) que les Tibétains nomment le $7^{e}$ Panchen Lama est appelé $10^{e}$ Panchen Lama par les Chinois. Dans le cadre de cet article, nous avons arbitrairement opté pour " $10^{e}$ Panchen Lama" car c'est ainsi que toute la presse chinoise le qualifiait. Il en va de même pour son successeur, le $11^{\mathrm{c}}$ Panchen Lama (qui est le $8^{\mathrm{e}}$ pour les Tibétains).

Une relation particulière nouait la lignée des Dalaï Lamas à celle des Panchen Lamas. Elle avait déjà commencé lorsqu'en 1642, le $5^{\text {e }}$ Dalaï Lama devint le chef spirituel et temporel du Tibet. Il entretenait alors une relation de disciple à maître avec le ler Panchen Lama. Après son avènement, il lui offrit le monastère de bKra-shis-lhun-po et la majorité des terres de la province du gTsang, assurant ainsi l'autosuffisance économique de son maître. À partir de ce moment, une relation de maître à disciple, s'inversant en fonction de l'âge des prélats, unit les deux lignées de réincarnation. La montée en puissance des Dalaï Lamas, chefs de l'école religieuse des dGe-lugs-pa, propulsa la lignée des Panchen Lamas au rang de seconde autorité spirituelle de cette même école. 
que plus de la moitié de l'A-mdo était assimilée au Qinghai. Le dBus-gTsang devenait la Région autonome du Tibet.

En novembre 1960, la réforme agraire fut déclarée « achevée et pleinement réussie » alors que, sur le terrain, des dizaines de milliers de Tibétains mouraient de faim après l'échec du Grand bond en avant. Les premières attaques contre les monastères du dBus-gTsang eurent lieu dès 1959. Les Chinois accumulaient les erreurs et ils allaient bientôt perdre leur seconde carte. À la fin de l'année 1960, le monastère de bKra-shis-lhun-po (siège abbatial de la lignée des Panchen Lamas) subit comme les autres les dévastations de l'Armée populaire de libération. Le $10^{\mathrm{e}}$ Panchen Lama réagit violemment contre les Chinois et se rangea du côté du $14^{\mathrm{e}}$ Dalaï Lama, alors qu'il avait été jusque-là un instrument docile du Parti communiste chinois et exerçait des fonctions honorifiques au sein des différentes commissions créées par la Chine au Tibet. En 1962, il rédigea un très controversé « Rapport en 70000 caractères » sur la situation tibétaine qui entraîna sa disgrâce et son emprisonnement (Tibet Information Network, 1998). D'autres actions d'éclat lui valurent d'être absent le jour de la création officielle de la Région autonome du Tibet, le 9 septembre 1965. Ngaphod Ngag-dbang 'Jigs-med accepta d'assurer la présidence de la nouvelle région autonome. Le $10^{\mathrm{e}}$ Panchen Lama fut longuement écarté de la scène politico-religieuse du Tibet. Manifestement, la politique chinoise et la religion tibétaine ne faisaient pas bon ménage et les autorités chinoises avaient échoué dans leur tentative de s'attacher les deux plus importants hiérarques de l'école dGelugs-pa au pouvoir au Tibet. Depuis, le Tibet, comme toute autre région autonome de la Chine, est administré par un gouvernement local et une assemblée populaire. Au moins un des postes de président ou de vice-président du Comité permanent de l'Assemblée populaire est attribué à un citoyen tibétain. Mais le poste de premier secrétaire du Parti communiste au Tibet revient toujours à un Chinois.

La période de la révolution culturelle (1966-1979) se passe de commentaires - les mêmes exactions furent commises en Chine et au Tibet. En revanche, l'année 1980 ouvrit une nouvelle page de l'histoire de ce pays.

En mars 1980, se tint la première « réunion de travail sur le Tibet », à l'issue de laquelle les représentants du gouvernement chinois décidèrent de " chercher la vérité dans les faits ». À ce titre, Hu Yaobang, secrétaire général du Comité central et Wan Li, membre du secrétariat du Comité central et vice-premier ministre au Conseil des affaires d'État, visitèrent le Tibet en mai 1980. Aux termes de leur tournée d'inspection, ils rendirent compte de l'état de la situation du peuple tibétain, en particulier de son extrême pauvreté, et proposèrent des solutions pour un redressement économique de la Région autonome. C'était la première fois que de hauts responsables du Parti communiste chinois se rendaient au Tibet et leur tournée d'inspection marqua un tournant décisif pour la situation politique et économique du Haut plateau : des mesures spécifiques au Tibet allaient être dorénavant appliquées, incluant un assouplissement de la politique religieuse. 
Ainsi, après la fin de la révolution culturelle, les autorités chinoises ont progressivement desserré l'étau des contraintes qui pesaient sur les pratiques religieuses au Tibet. Dans un premier temps, elles ont timidement modéré leur position. Puis, de mai 1980 (date de la visite de $\mathrm{Hu}$ Yaobang au Tibet) à mars 1989 (date des émeutes nationalistes de Lhasa), elles ont fait preuve d'une certaine ouverture d'esprit, tolérant un renouveau religieux au Tibet et n'opérant qu'un contrôle atténué sur le nombre des moines et des monastères. Les émeutes de mars 1989 ont sonné le glas de cette période de relative tolérance. La polémique concernant la reconnaissance du $11^{\mathrm{e}}$ Panchen Lama et la fuite récente de plusieurs hiérarques religieux en Inde ont alourdi le climat dans la Région autonome du Tibet.

\subsection{UN ENCADREMENT JURIDIQUE ÉTROIT DE LA LIBERTÉ DE CROYANCE}

À défaut d'avoir pu contrôler les $14^{\mathrm{e}}$ Dalaï Lama et $10^{\mathrm{e}}$ Panchen Lama, les autorités chinoises ont choisi d'appliquer la même politique de liberté de croyance religieuse au Tibet et en Chine sans plus tenir compte des spécificités religieuses et culturelles tibétaines. De fait, la politique commençait à prendre le pas sur la religion.

Dans l' «Accord en 17 points concernant la libération pacifique du Tibet » du 23 mai 1951, les autorités chinoises affirmaient qu'elles ne modifieraient pas le système politique tibétain tel qu'il existait alors, pas plus que le «statut établi », les fonctions et pouvoirs du Dalaï Lama. Elles promettaient de laisser les fonctionnaires de divers rangs à leur poste (article 4) et de maintenir le « statut établi ", les fonctions et les pouvoirs du Panchen Lama (article 5) ${ }^{3}$. Dans l'article 7, elles annonçaient la mise en place d'une politique de liberté de croyance religieuse telle que définie dans le programme commun de la Conférence consultative politique du peuple chinois (CCPPC). Elles s'engageaient à respecter « les croyances religieuses, les coutumes et les habitudes du peuple tibétain », à « protéger les monastères lamaïstes » et à « ne pas changer le mode de revenus des monastères ».

La tendance générale inaugurée dans l' «Accord en 17 points » fut confirmée par la première Constitution chinoise de septembre 1954, d'après laquelle « chaque citoyen de la République populaire de Chine bénéficiera de la liberté de croyance religieuse ».

La révolution culturelle mit un terme à toute pratique religieuse et la deuxième Constitution chinoise de 1975 n'apporta rien de nouveau en la matière, pas plus que la troisième (datée du 5 mars 1978). En décembre 1978, le $11^{\mathrm{e}}$ Plénum du $11^{\mathrm{e}}$ Comité central du Parti communiste chinois autorisa une

3. Selon les autorités chinoises, les « statuts établis, fonctions et pouvoirs des Dalaï Lamas et des Panchen Lamas » étaient ceux des $13^{\mathrm{e}}$ Dalaï Lama et $9^{\mathrm{e}}$ Panchen Lama « quand ils étaient en bons termes » (article 6). 
timide reprise de la vie religieuse. Un faible nombre de monastères furent réouverts au Tibet.

Après la visite de la Région autonome du Tibet effectuée par Hu Yaobang et Wan Li, la quatrième Constitution chinoise (datée du 4 décembre 1982) marque une volonté d'assouplir et de normaliser la politique religieuse. Son article 36 stipule que « les citoyens de la République populaire de Chine jouissent de la liberté de croyance religieuse. Aucun organisme d'État, aucun groupement social, aucun individu ne peut contraindre un citoyen à épouser une religion ou à ne pas la pratiquer, ni adopter une attitude discriminatoire à l'égard du citoyen, croyant ou non-croyant. L'État protège les pratiques religieuses normales. Nul ne peut se servir de la religion pour troubler l'ordre social, nuire à la santé des citoyens ou entraver l'application du système d'enseignement de l'État». Par ailleurs, l'article 147 du code pénal précise « la protection de la liberté des cultes et l'égalité des droits des citoyens croyants »: «Les fonctionnaires d'État qui violent la liberté de culte du citoyen ou qui violent les coutumes des minorités nationales, dans les cas graves, peuvent être punis d'une peine d'emprisonnement de deux ans maximum ou d'une peine d'emprisonnement de courte durée. Quiconque empêche par la force des activités religieuses légales, oblige des croyants à abandonner leur religion, contraint un citoyen à pratiquer un culte quelconque, ferme illégalement ou démolit des lieux de culte légaux ou d'autres installations religieuses, viole les droits démocratiques, la liberté individuelle et manque au devoir, sera sanctionné par la loi ».

Deux nouveaux règlements sur les activités religieuses entrèrent en vigueur le 31 janvier 1994. Le premier régit les activités religieuses des ressortissants étrangers à l'intérieur des frontières de la République populaire de Chine. Le second est relatif au fonctionnement des lieux de culte (décret no 145 du Conseil d'État). Il traduit la volonté des autorités chinoises d'accroître leur contrôle sur la vie religieuse tibétaine, après la période de relative clémence allant de 1980 à 1989. Il se fixe pour objectifs de protéger « les activités religieuses normales » (sans véritablement définir cette notion) et de garantir aux organisations religieuses le droit de recevoir des dons, de vendre des objets à caractère religieux et de gérer elles-mêmes leurs biens et revenus. L'article 2 indique que « tous les lieux consacrés aux activités religieuses » - temples, monastères, mosquées, églises ou autres emplacements où se déroulent des activités religieuses - doivent être déclarés auprès des autorités, selon les règles fixées par le bureau gouvernemental des affaires religieuses. Selon l'article 3, les « droits juridiques des organisations religieuses ainsi que les activités religieuses normales (...) seront protégés par la loi; nulle organisation ou personne ne sera autorisée à enfreindre les uns ou entraver les autres ». Quant à l'article 4, il interdit toute activité « qui nuise à l'unité nationale ou ethnique, à l'ordre social ou à la santé du citoyen ou qui détruise le système d'éducation nationale ». De la sorte, les autorités chinoises cherchent à juguler toutes les activités nationalistes engagées par la communauté monastique bouddhiste de la Région autonome du Tibet à partir de 1988-1989. 
Plus récemment, le 22 juin 2000, le Bureau d'information du Conseil d'État de la République populaire de Chine a publié un livre blanc intitulé Le développement de la culture tibétaine. Dans ce document, les autorités chinoises déclarent que «les coutumes indigènes et la liberté de croyance religieuse sont respectées et protégées » au Tibet. Elles précisent que «chaque année, des activités et des fêtes religieuses importantes sont célébrées dans la Région autonome du Tibet. La branche tibétaine de l'Association bouddhique de Chine contrôle maintenant sept sous-branches au niveau des préfectures, le journal du bouddhisme au Tibet rédigé en tibétain, un institut de théologie bouddhique et une maison d'édition des sutras ». Enfin, les autorités chinoises contrôlent également la maturité des moines puisque l'âge minimum requis par la loi pour entrer au monastère est de dix-huit ans.

Ces lois definissent un cadre très strict pour l'exercice de la religion tant en Chine qu'au Tibet et laisse très peu de marge à l'expression de la foi individuelle. Leur application traduit à l'évidence une volonté d'anéantissement de la religion bouddhique au Tibet car le nationalisme tibétain s'exprime à travers elle.

\section{LES MONASTÈRES SOUS SURVEILLANCE}

\subsection{LA COLLECTIVISATION DES TERRES MONASTIQUES ET L'AF- FAIBLISSEMENT DE L'ASSISE ÉCONOMIQUE DES MONASTĖRES}

Le monastère occupait une place centrale dans la vie politique, religieuse et économique tibétaine d'avant 1959. À partir de 1950, plus que les déprédations commises sur le terrain (par l'Armée populaire de libération chinoise et les gardes rouges), le gouvernement chinois prit une décision lourde de conséquences pour le fonctionnement quotidien des monastères. Il procéda à la confiscation de toutes les terres monastiques pour les redistribuer aux paysans-contribuables qui travaillaient sur ces terres ${ }^{4}$.

Priver le monastère de sa source de revenu principal revenait à l'empêcher de fonctionner. En effet, selon le prestige acquis par la lignée d'un maître réincarné (ou d'un abbé), son monastère pouvait bénéficier de dons de terres (« les terres collectives »). Il en allait de même pour les monastères plus petits dépendant du premier, pour chacun de ses collèges et pour chacune de ses maisonnées de moines. Dans ces deux derniers cas, le donateur de la terre appartenait souvent à la famille d'un moine du collège ou de la maisonnée concernée. Ces terres offertes étaient soumises à l'impôt ou ne l'étaient pas (Carrasco, 1959. p. 104 ; Surkhang, 1986, p. 23). Les paysans-contribuables devaient exécuter les corvées.

4. Le $10^{c}$ Panchen Lama, alors présent à Pékin, aurait tenté d'intervenir en proposant de substituer un salaire aux revenus fonciers des moines (supprimés du fait des réformes) afin de permettre aux monastères de poursuivre leurs activités religieuses, mais sans résultat (SHAKYA, 1999). 
À ces revenus fonciers s'ajoutaient ceux versés par le gouvernement tibétain qui consacrait près de $£ 1000000$ de son budget total aux monastères (Bell, 1987, pp. 187-188). Il arrivait également que des monastères aient droit à des offrandes de beurre ou de grains après collecte des impôts au niveau du district (Surkhang, 1986, p. 26). La production agricole de ces terres constituait la principale source de revenus des monastères et servait, entre autres, à nourrir les moines lors des cérémonies quotidiennes et des fêtes religieuses. Hormis ces moyens de subsistance, les moines recevaient des dons en provenance de leur famille et des pèlerins. Sinon, ils subvenaient eux-mêmes à leurs besoins en recourant, par exemple, à des rituels qu'ils célébraient à l'intention des laïcs et qui constituaient pour eux un moyen de susciter les offrandes (Samuel, 1993, pp. 210-211) ou au commerce. Ainsi, dépourvus de leur revenu de base, les monastères se vidèrent et les moines furent obligés de se séculariser.

Les chiffres confirment également que la collectivisation s'est accompagnée de la destruction de nombreux monastères. De 1959 à 1976, les monastères tibétains ont particulièrement souffert. L'Accord en 17 points ne fut pas respecté par les autorités chinoises en place au Tibet puisque la majorité des destructions de monastères eut lieu non pas pendant la révolution culturelle, mais entre 1959 et 1966. Le nombre de monastères restant debout en 1966 ne s'élevait plus qu'au quart de leur nombre initial (en 1959, celui-ci allait de 2176 à 2500 [Beijing Information, 26/10/1987 ; Tibet Information Network, 11/6/ $1998{ }^{5}$ ]). Selon les autorités chinoises, « beaucoup de monastères et de temples furent détruits par des serfs tibétains, qui se vengèrent de l'oppression [supposée être exercée contre eux par les aristocrates tibétains ou les prélats propriétaires terriens] »(Beijing Information, 26/10/1987) !

Aujourd'hui, nombre de monastères tibétains sont en cours de reconstruction et de réhabilitation. Le financement de la réfection des plus grands d'entre eux (Po-ta-la, Jo-khang, Se-ra, 'Bras-spungs, dGa'-ldan, bKra-shis-lhun-po, sKu'bum, Bla-brang bkra-shis-kyil, etc.) est assuré par le gouvernement chinois (Renmin ribao, 12/09/1987, 12/10/1989, 24/12/1989). De 1989 à 1994, les autorités chinoises auraient alloué 55 millions de yuans pour restaurer le Po-ta-la. Actuellement, elles consacreraient de 4 à 5 millions de yuans par an pour la protection des reliques religieuses du Tibet (Livre blanc, 22/6/2000). Pour ce qui est des petits monastères de villages, les travaux de restauration sont financés et exécutés par les villageois et les moines eux-mêmes. Cependant, il semble que les monastères aient passablement perdu leur vocation initiale. De lieux de transmission de la pensée bouddhique et de débat philosophique, ils sont aussi devenus des lieux touristiques, des musées (tel que le monumental Po-ta-la), voire des entreprises commerciales qui, privées de leurs terres agricoles, monnayent leur production artisanale d'objets d'art (sculptures, tentures d'appliqués bouddhiques) ou de tapis (comme le monastère de bKra-shis-lhunpo, à gZhis-ka-rtse, ou celui de sKu-'bum, près de Xining), cela avec les encouragements du gouvernement chinois.

5. M. Van Walt van Praag (1987) annonce le chiffre aujourd'hui contesté de 6254. 
De nos jours, le nombre de monastères en activité (partielle ou pleine) au Tibet est assez difficile à déterminer tant les chiffres sont contradictoires selon l'origine des sources. En novembre 1988, l'ouvrage intitulé Le Tibet, 100 questions et réponses mentionne le chiffre de 1142 monastères, à comparer aux 200 de l'essai Transfert de population et survie de l'identité tibétaine présenté le 13 juin 1986 par le Dr. Van Walt van Praag au 7e Symposium annuel international sur les Droits de l'Homme. En novembre 1994, interrogés par le rapporteur spécial de la Commission des droits de l'homme de l'ONU, le Bureau des affaires religieuses chinois et la Conférence consultative politique du peuple chinois (CCPPC) indiquent tous deux le chiffre de 3000 monastères. Le document publié en décembre 1994 par le rapporteur spécial précise que, selon les autorités chinoises, « 1400 lieux de cultes ont été restaurés et réouverts » (Rapport E/CN.4.1995/91.20/12/1994). En juin 1998, l'Organisation non gouvernementale Tibet Information Network, citant une source chinoise indéterminée, avance le chiffre de 1781 , soit « 300 de plus qu'en $1951 »$. Pour finir, le livre blanc sur Le développement de la culture tibétaine, daté du 22 juin 2000 et publié par le Bureau d'information du Conseil d'État chinois, annonce que « le Tibet abrite maintenant plus de 1700 monastères, temples et autres sites à caractère religieux », apportant la preuve que les chiffres officiels de 1994 étaient surévalués.

Si le nombre de monastères en activité dans la Région autonome du Tibet est aujourd'hui entaché d'incertitudes, l'organisation de ces monastères et le contrôle politique qui s'y exercent sont en revanche mieux connus. Depuis 1960 , chaque grand monastère tibétain est géré par un Comité de gestion démocratique (CGD). Il est composé d'un directeur, d'un ou de plusieurs directeursadjoints et de plusieurs membres qui, en théorie, sont élus pour trois ans par tous les moines du monastère (Mengzi, 1993, p. 100). En pratique, ils sont souvent nommés par le Bureau des affaires religieuses locales (sous contrôle du PCC) comme ce fut le cas en 1989 après les émeutes de Lhasa ou lors des périodes de fortes tensions politico-religieuses. Dans les grands monastères de Lhasa, durant les crises, ils ont parfois été remplacés par des membres de la police (Rapport du Conseil économique et social des Nations Unies, 18/1/1991, p. 79). Seules les candidatures approuvées par le Parti communiste local sont valides (Tibet Information Network, Briefing Paper $n^{\circ} 25,1995$, p. 15). Les responsabilités religieuses et administratives se répartissent entre des souscomités en charge des activités bouddhiques (enseignements, prières, etc.), de la conservation des reliques, du respect de la discipline, de la gestion financière, de l'entretien des bâtiments et de la production artisanale (Mengzi, 1993, p. 101 ; Tibet Information Network, Briefing Paper $n^{\circ} 25,1995$, p. 16). Au monastère de 'Bras-spungs, par exemple, en 1995, le CGD était constitué de quinze personnes. De fait, chaque grand monastère peut administrer des plus petits. Par exemple, outre sa propre structure, bKra-shis-lhun-po gère plusieurs petits monastères de la région du gTsang tels que ceux de Phun-tshogs-gling, lHa-rtse ou rGyal-rtse. À Lhasa, les CGD des trois grands monastères ('Brasspungs, dGa'-ldan, Se-ra) rendent compte de leurs activités à l'antenne du 
Bureau des affaires religieuses de Lhasa. Quant au Bureau des affaires religieuses, il appartient au Conseil des affaires d'État. Il est chargé d'appliquer la loi et la politique relatives à la liberté de croyance religieuse. Il est surveillé par le Congrès du peuple et la CCPPC. Par ailleurs, une Association bouddhiste chinoise (ABC), qui compte environ un tiers de membres tibétains, existe depuis 1953. Elle sert d'intermédiaire entre la communauté bouddhiste et le gouvernement chinois. Son rôle semble essentiellement consultatif. Une branche fut ouverte à Lhasa dès 1957 (Goldstein \& Kapstein, 1988). Aujourd'hui, on en compte sept au Tibet. Le $10^{\mathrm{e}}$ Panchen Lama en fut le président honorifique de 1963 à 1989, année de sa mort.

\subsection{UNE POPULATION MONASTIQUE EN NETTE DIMINUTION}

Les destructions de monastères, la confiscation de leurs terres et les mesures politiques de recrutement des moines et des moniales affaiblirent considérablement les effectifs de la population monastique. Le nombre des moines et moniales a chuté de façon vertigineuse de 1959 à 1966 (passant de 114107 à 6913) et plus encore de 1966 à 1976 pour n'atteindre que 900 individus. Les moines seraient volontairement rentrés dans le monde (Beijing Information, 26/10/ 1987). Disons, plus prosaïquement, que nombre d'entre eux renoncèrent à leurs vœux pour prendre les armes au cours du soulèvement de 1959 et aussi que 7000 moines suivirent le 14 ${ }^{\mathrm{e}}$ Dalaï Lama dans son exil en Inde en 1959. Ces faits n'expliquent évidemment pas la disparition des 106207 moines restants, puisque les Tibétains et les Chinois s'accordent à peu près sur leur nombre initial (120 000 à comparer à 114 107). En fait, nombreux sont ceux qui moururent en 1959 : 87000 morts tibétains, laïcs et religieux, furent dénombrés. On a pu également estimer à 173221 personnes le nombre de Tibétains laïcs et religieux à avoir passé une vingtaine d'années en prison ou dans des camps de travaux forcés et à y périr (Van Walt van Praag, 1987) sachant que les moines constituaient la cible privilégiée du Parti communiste chinois.

Aujourd'hui, seuls les chiffres concernant la population religieuse des grands monastères dGe-lugs-pa ('Bras-spungs, dGa'-ldan, Se-ra) sont facilement vérifiables sur place. En 1959, le nombre total des moines de 'Bras-spungs, dGa'ldan, Se-ra et bKra-shis-lhun-po avoisinait 23000 personnes, à comparer aux 120000 en exercice à cette époque se répartissant dans les quelques 2500 monastères disséminés à travers le territoire tibétain.

En août 1988, nous avons visité les monastères de Se-ra et 'Bras-spungs : quelques dizaines de moines paraissaient occuper les lieux. En janvier (et en juillet) 1993, au monastère de sKu-'bum, nous avons pu constater au cours d'une grande fête bouddhique que cette institution abritait environ 500 moines, à comparer aux plusieurs milliers qui vivaient là avant 1959. En juin 1993, nous sommes allés aux monastères de dGa'-ldan et de bKra-shis-lhun-po; dGa'-ldan semblait désert. Quant à bKra-shis-lhun-po, comme sKu-'bum, il était peuplé de plusieurs centaines de moines. Ces quatre grands monastères abriteraient au 
total de 1550 à 1950 moines. En prenant l'hypothèse haute de la fourchette, en la comparant aux 23000 moines qui peuplaient les mêmes lieux en 1959 et en la rapportant aux 120000 moines tibétains de 1959, une simple règle de trois indique que la population totale des moines en exercice au Tibet d'aujourd'hui serait d'environ 10000 personnes. Ce chiffre est à rapprocher des 30000 (Renmin ribao, 24/12/1989), des très optimistes 120000 (Bureau des affaires religieuses et CCPC, 11/1994) et, plus près de nous, des 46000 (Livre Blanc, 22/6' 2000) officiellement cités.

D'une façon pragmatique, notre total de $1550-1650$ moines en exercice dans les quatre grands monastères ('Bras-spungs, dGa'-ldan, Se-ra, bKra-shislhun-po) est cohérent avec le nombre de moines ayant participé à la fête de la Grande Prière, qui est le plus grand rassemblement de religieux et de pèlerins de l'année au Tibet (en 1986: 1000 moines; en 1987: 1800 moines; en 1988: 1600 moines [Renmin ribao, 26/2/1986, 17/3/1987, 28/2/1988]).

\subsection{LE CONTRÔLE MULTIFORME DES ACTIVITÉS RELIGIEUSES DES MONASTÈRES}

Le contrôle des autorités sur les activités religieuses des monastères revêt de multiples aspects. Il concerne à la fois les conditions d'accès à l'état monastique avec le régime de l'ordination, l'enseignement et les pratiques religieuses.

Après l'imposition de la loi martiale à Lhasa le 7 mars 1989, la population monastique connut à nouveau des heures sombres. L'armée chinoise prit le contrôle des grands monastères de Lhasa où tous les religieux étaient assignés à résidence. À partir de ce moment, le Bureau des affaires religieuses de Lhasa (épaulé par le comité local du Parti communiste) entreprit de contrôler plus sévèrement les autorisations de rénovation des monastères ainsi que leurs revenus, la nomination des abbés et des membres des CGD, la sélection des candidats moines dont l'âge minimum fixé à 18 ans fut strictement vérifié, le nombre des religieux vivant au monastère et le règlement intérieur. Les autorités installèrent des unités de police au sein même des monastères, afin de démasquer les moines pro-nationalistes. Plusieurs centaines de moines furent jetés en prison ou expulsés de leur monastère (Rapport du Conseil économique et social des Nations Unies, 18/1/1991, p. 79). En avril 1990, 200 moines et moniales soupçonnés de sympathies nationalistes furent expulsés. Afin d'être admis dans un monastère, un aspirant moine doit, outre les conditions d'âge précitées, montrer qu'il aime son pays et le Parti communiste chinois; avoir le consentement de ses parents; obtenir l'accord du CGD du monastère, celui des autorités provinciales, celui du Bureau de la sécurité publique; ne pas avoir été impliqué dans des activités pro-indépendantistes; postuler dans un monastère de sa région d'origine (Bureau du 14 ${ }^{\mathrm{e}}$ Dalaï Lama, 2/2/1996). Ceux qui parviennent à entrer dans les ordres et optent pour l'étude du bouddhisme à plein temps perçoivent un salaire (à 'Bras-spungs, ce salaire serait de 150 yuans par mois). Quant à leurs maîtres, avant d'obtenir le droit de dispenser un enseignement ou de 
conduire une cérémonie spécifique, ils doivent en faire la demande officielle auprès du Bureau des affaires religieuses locales. De la sorte, maîtres comme élèves restent très encadrés.

Le rapport préliminaire du $3^{e}$ Forum de travail sur le Tibet (1994), qui fixa les objectifs politiques annuels du gouvernement de la Région autonome du Tibet pour les années 1996 et 1997, indiquait que « à présent, le nombre des monastères, moniales et moines au Tibet est suffisant pour couvrir les besoins quotidiens concernant les pratiques religieuses du peuple et, à ce sujet, nous devrions continuer à travailler patiemment sans relâcher notre contrôle » (Tibet Information Network, 11/6/1998).

En réalité, depuis 1994 , le gouvernement chinois semble opérer un contrôle rigoureux des activités religieuses au Tibet. Le nombre respectif d'ordinations, de moniales et de moines et de monastères en activité est sévèrement contingenté. Certains monastères ont été fermés par les autorités chinoises (Tibet Information Network, 11/6/1998). Depuis la fuite du $17^{\mathrm{e}} \mathrm{Karmapa}$ en décembre 1999, les contrôles se sont intensifiés. 11409 moines et moniales auraient été expulsés de leur monastère et 20 lieux de culte auraient été fermés (Bureau de représentation du 14e Dalaï Lama, Londres, 12/1999).

Jusqu'en 1959, le monastère était un lieu de rencontres, d'échanges religieux, culturels et politiques. C'est vers lui que convergeaient les pèlerins. Son importance était telle que certains d'entre eux ('Bras-spungs, dGa'-ldan, Se-ra, bKra-shis-lhun-po, sKu-'bum, Bla-brang bkra-shis-kyil) constituaient de véritables villes, peuplées de milliers de moines. Le monastère offrait avant tout une structure d'encadrement pour la transmission des textes bouddhiques, il était un lieu d'enseignement.

L'enseignement traditionnel tibétain, tel qu'il était dispensé avant 1959, comprenait l'apprentissage de l'art dramatique, la danse et la musique, l'astrologie, la poésie et la composition. Dans le cadre de l'enseignement supérieur, les cours incluaient le sanscrit, la médecine, la dialectique, l'art et l'artisanat, la métaphysique et la philosophie religieuse. Les études exigeaient une vingtaine d'années d'efforts assidus. Le moine devait d'abord mémoriser les textes fondamentaux qui étaient ensuite expliqués par un maître qu'il avait librement choisi. Puis des discussions étaient organisées afin que les élèves puissent débattre entre eux, en présence de leurs maîtres qui réexpliquaient les points demeurés obscurs. Les études philosophiques étaient couronnées dans les trois grands monastères dGe-lugs-pa par les examens de dge-bshes (il existait plusieurs degrés) qui consistaient en une série de questions-réponses se succédant à un rythme très rapide. Les premiers grades étaient accordés par le monastère d'origine, alors que le titre de dge-bshes lha-ram-pa (docteur en philosophie) était décerné au cours du Fcstival de la grande prière. Le candidat était alors soumis à des débats devant des milliers de moines qui pouvaient tous le questionner. Dans les autres collèges non philosophiques, les moines se consacraient aux récitations de prières et à la méditation. 
De la sorte, avant 1959 , toute vie éducative et culturelle était définie par rapport à la religion ${ }^{6}$. Aujourd'hui, si le gouvernement chinois considère que la religion ne doit pas s'ingérer dans la politique, il n'hésite pas à insérer un cours de « connaissances élémentaires de politique » dans le cadre d'un enseignement religieux dispensé dans un monastère. Le 27 mai 1983, le Conseil des affaires d'État autorisa la création d'un institut bouddhique dans le monastère de 'Brasspungs à Lhasa (Renmin ribao, 28/5/1983). Des maîtres réincarnés et des moines de toutes les branches du bouddhisme tibétain y étudient. Le programme de l'enseignement primaire comporte les textes fondamentaux de la religion, la langue tibétaine, des connaissances culturelles et des bases élémentaires de politique. Les classes de perfectionnement ont à leur programme les théories religieuses et le tibétain classique. Le cursus scolaire dure dix ans. À cela s'ajoute une année d'enseignement supérieur dispensée à Pékin depuis le 2 septembre 1987, date à laquelle l'Institut supérieur d'étude du bouddhisme tibétain y fut inauguré (Renmin ribao, 2/9/1987) ${ }^{7}$.

Aujourd'hui, bien que l'Institut bouddhique de Lhasa ait été aménagé dans le monastère de 'Bras-spungs, il est étroitement contrôlé par les autorités chinoises (les attaques dont son bureau de la rue du Parkor à Lhasa a fait l'objet au cours des manifestations de mars 1988 et mars 1989 en témoignent). Ses cours s'appuient sur quatre ouvrages qui traitent de « la vraie histoire du Tibet » (revisitée par le Parti communiste chinois), la « religion», le «droit » et le « séparatisme » (Le Monde diplomatique, 1997). Des structures équivalentes à celle de 'Bras-spungs existent dans les monastères de sKu-'bum, de Bla-brang bkrashis-'kyil et de bKra-shis-lhun-po. Dans les petits monastères, la transmission des enseignements bouddhiques paraît plus aléatoire. D'ailleurs, une des principales raisons invoquées par le $17^{\mathrm{e}} \mathrm{Karmapa}$ pour expliquer sa fuite du Tibet en décembre 1999 est qu'il n'était pas en mesure de recevoir un enseignement conforme à la tradition de sa lignée faute de maître qualifié.

Après 1989, l'éducation politique des moines s'est intensifiée. Elle est assurée par des "équipes de travail" composées de membres tibétains du Parti communiste, eux-mêmes dirigés par des cadres chinois spécialisés (Tibet Information Network, Briefing paper $n^{\circ} 25,1994$, p. 15). Les moines sont obligés de participer aux réunions hebdomadaires d'éducation politique (Rapport de la Commission des droits de l'homme de l'ONU, 18/1/1991). S'ils ne s'y présentent pas, ils doivent payer une amende. Au-delà de trois absences injustifiées, ils sont expulsés du monastère. Le rôle des "équipes de travail" ne se limite pas à l'éducation politique. Elles sont aussi chargées de repérer les moines gagnés à la cause nationaliste. Souvent, elles rendent compte directement au Bureau de la sécurité publique locale (Shakya, 1989). Ainsi l'ingérence du monde politique dans les institutions religieuses tibétaines est double. D'une part, les autorités

6. Cependant, seulement $10 \%$ des moines auraient véritablement étudié les textes bouddhiques, les autres devant subvenir à leurs besoins.

7. 37 moines sur les 42 inscrits en 1987 recevront des mains du $10^{e}$ Panchen Lama, président de l'Institut, leur diplôme en juin 1988 (Renmin ribao, 14/6/1988). 
chinoises imposent aux élèves de l'Institut bouddhique de Lhasa une "vraie histoire du Tibet » expurgée de ses périodes et faits "politiquement incorrects". D'autre part, elles interviennent directement dans la sélection des abbés et des membres des CGD et exercent une surveillance étroite sur la communauté monastique.

La liberté de croyance religieuse a été officiellement autorisée à nouveau au Tibet lors du $3^{\mathrm{e}}$ plénum du XI ${ }^{\mathrm{e}}$ Comité central (10-12 décembre 1978). À cette occasion, de nombreux religieux ont été libérés ou réhabilités afin que les offices puissent être célébrés selon la liturgie du bouddhisme tibétain. Certains hauts dignitaires, tel le $10^{\mathrm{e}}$ Panchen Lama, ont même obtenu des postes de représentants à l'Assemblée nationale populaire. Interdit depuis 1966, le Festival de la grande prière a été rétabli en 1986, décision marquant le retour officiel de la pratique religieuse au Tibet. Cela a permis au $10^{\mathrm{e}}$ Panchen Lama de retrouver l'important rôle religieux qu'il avait perdu. Six articles parus dans le Renmin ribao ont couvert cet événement qui s'est déroulé du 26 février au 6 mars 1986. Pour avoir attendu vingt ans avant d'autoriser de nouveau cette fête, le gouvernement chinois devait, à l'évidence, craindre des débordements. Ces craintes étaient fondées car si la fête de l'année 1987 s'est terminée dans la joie, celles de 1988 et 1989 se sont achevées par des manifestations violentes : les 5 mars 1988 et 1989, les Tibétains ont choisi le dernier jour du Festival de la grande prière pour clamer bruyamment leur mécontentement. Quant à celle de 1990 , elle fut annulée pour cause de loi martiale. Elle serait à nouveau célébrée (Livre Blanc, 22/6/2000).

La photographie du $14^{\mathrm{e}}$ Dalaï Lama, que ce soit dans les monastères ou dans les foyers, occupe une place importante. Malgré la durée de son exil, le prélat jouit toujours d'une grande popularité dans le cœur des Tibétains. Depuis le troisième Forum sur le Tibet de juillet 1994, il est interdit d'exposer en public (ou en privé) des représentations du $14^{\mathrm{e}}$ Dalaï Lama (Tibet Information Network, 1996, p. 38). Il semble qu'au cours des derniers mois, cette mesure ait été renforcée, surtout depuis la fuite du $17^{\mathrm{e}}$ Karmapa.

Très pieux, les nomades tibétains sont friands de grands pèlerinages, comme celui du mont Kailash. Depuis 1980, ces pèlerinages avaient été progressivement tolérés par les autorités chinoises, jusqu'aux émeutes de 1989. Puis, après la levée de la loi martiale, ils avaient peu à peu repris. Des témoignages récents rapportent que la liberté de circuler est de nouveau entravée dans la Région autonome du Tibet, ce qui rend la pratique des pèlerinages très problématique. Somme toute, la liberté de croyance religieuse est toujours battue en brèche au Tibet. Comment les maîtres réincarnés qui vivent dans ce pays réagissent-ils à cette situation? 


\section{MANGUVRES ET TRACTATIONS AUTOUR DES MAÎTRES RÉIN- CARNÉS ${ }^{8}$}

\subsection{LE RÔLE RELIGIEUX ET POLITIQUE SPÉCIFIQUE DES MAÎTRES RÉINCARNÉS}

Les maîtres réincarnés avaient une influence considérable sur la vie spirituelle, politique et sociale tibétaine. Il est donc essentiel de savoir quelles étaient, par le passé, leurs activités religieuses et politiques afin de mieux saisir les raisons qui poussèrent les autorités chinoises à s'immiscer dans le processus de leur reconnaissance et à leur donner un rôle politique grandissant.

Dans la tradition bouddhiste, il est dit que pour obtenir l'Éveil, il faut accumuler des mérites et de la sagesse. L'accumulation de la sagesse signifie développer la compréhension de la vacuité de toutes choses. L'accumulation de mérites s'accomplit par la pratique régulière de dons, d'offrandes, et par le développement de qualités telles que l'amour, la compassion, la générosité, l'éthique, la patience, etc. Les bouddhistes, qui tentent de conformer leur vie aux instructions léguées par le Bouddha Shâkyamuni, placent toute leur confiance (l'expression consacrée étant «qu'ils prennent refuge ») dans les Trois Joyaux (Bouddha, Dharma, Sangha) qu'ils vénèrent. Ils comparent le Bouddha au médecin capable de délivrer le malade de la souffrance; le Dharma (ou Loi, ou Enseignement du Bouddha) au traitement prescrit par le médecin; et la Sangha (la communauté des nonnes et des moines) à l'infirmière qui entoure le malade de ses soins et de son affection. Selon eux, faire des offrandes aux Trois Joyaux se révèle très bénéfique. Les disciples qui s'adonnent à cette pratique accumulent une grande quantité de mérites et augmentent significativement leurs chances d'atteindre l'Éveil.

Dans le bouddhisme, il existe de multiples façons de procéder pour faire une offrande au Bouddha. En général, les disciples aménagent chez eux un petit autel sur lequel ils placent une représentation, que ce soit une statue ou une peinture. Quotidiennement, ils disposent devant la représentation du Bouddha les sept offrandes traditionnelles composées d'une coupelle d'eau, d'un peu de

8. C'est aux alentours du $x I^{\mathrm{e}}$ siècle que le principe de la renaissance consciente aurait vu le jour au Tibet. Il ne connaîtrait pas d'équivalent en dehors du Tibet. Dans le bouddhisme tibétain, un sprul-sku est un être humain dont l'incarnation précédente aurait parfaitement maîtrisé les émotions obscurcissantes de son esprit, aurait atteint les plus hautes réalisations spirituelles au cours de sa vie antérieure et aurait réalisé le "Corps de la loi » d'un Bouddha au moment de sa mort. De plus, l'esprit de l'incarnation précédente de cet être humain aurait réalisé le "Corps de félicité » d'un Bouddha au moment de sa traversée du bar-do et aurait choisi en toute conscience de se réincarner, par compassion pour ceux qui souffrent, dans un nouveau corps humain librement adopté dès l'instant de sa conception par ses géniteurs, plutôt que de jouir de sa vérité dans les "paradis de Bouddha » comme le feraient les déités du sambhogakaya (plutôt que de subir une renaissance conditionnée par la force de ses karma dans l'un des six mondes du Samsara, ce qui serait le sort réservé aux êtres ordinaires, prisonniers du cycle des existences). Selon les bouddhistes tibétains, les Dalaï Lamas et les Panchen Lamas sont des sprul-sku. 
nourriture, de quelques fleurs, d'encens, de parfum, d'une bougie allumée (qui matérialise l'offrande de lumière) et d'une clochette (qui représente l'offrande de musique). D'ordinaire, les Tibétains symbolisent ces offrandes par sept bols de cuivre qu'ils remplissent d'eau le matin et vident le soir. Par ailleurs, pourvoir aux besoins matériels de moniales et de moines, aider à la construction de logements monastiques, constituent pour les bouddhistes autant de possibilités d'effectuer des offrandes à la communauté religieuse.

En réalité, ils considèrent que des Trois Joyaux, le Dharma est le plus important car seule sa mise en application permet aux disciples de se libérer du Samsara (du cycle des existences conditionnées) et d'atteindre l'Éveil. Participer à l'impression ou à l'édition de textes bouddhiques, s'associer à l'organisation d'un enseignement, sont des actes qui peuvent faire office d'offrandes au Dharma. Mais, selon les bouddhistes, verser des dons au bla-ma afin qu'il puisse enseigner le Dharma dans les meilleures conditions se révèle bien plus bénéfique. En effet, l'unique mission du bla-ma est d'enseigner le Dharma afin de libérer tous les êtres de la souffrance et de les conduire au plein Éveil. Sans le bla-ma, qui est le digne ambassadeur des Bouddha dans le monde phénoménal, il n'y a pas de Dharma. Aussi, faire une offrande au bla-ma revient à honorer le Dharma. Répété, ce geste présente un double intérêt : d'une part, il permet au bla-ma de s'affranchir des contraintes matérielles et de consacrer sa vie à enseigner la doctrine et à favoriser sa diffusion; d'autre part, il donne aux disciples l'occasion d'exercer leur générosité et d'accumuler un grand nombre de mérites. Si leurs moyens ne leur permettent pas d'offrir des dons matériels au bla-ma, les disciples ont encore la possibilité de le servir et/ou de le protéger. En tout état de cause, ils doivent le respecter et agir selon les instructions du Dharma qu'il dispense. Bien entendu, ils restent libres de décider de la teneur et de la fréquence de leurs dons. Ils ne versent de dons au bla-ma que s'ils estiment que l'enseignement de ce dernier est profitable à la communauté et leur permet de lutter efficacement contre leurs propres souffrances. Si l'enseignement prodigué par un bla-ma ne correspond pas (ou plus) à ce que ses disciples en attendent, ceux-ci sont en droit de l'abandonner. Ce faisant, ils privent le bla-ma de leurs dons, ce qui peut le contraindre à mettre un terme à ses activités religieuses. À l'opposé, lorsqu'un bla-ma dispense un enseignement d'une grande qualité que ses disciples goûtent à sa juste valeur, lorsque, de plus, il a un comportement en pleine conformité avec la parole du Bouddha qu'il enseigne, alors les dons affluent et son monastère connaît une période de prospérité.

En résumé, la principale mission du bla-ma consiste à enseigner le Dharma sans rien attendre en échange. De son côté, le disciple est libre de lui faire des offrandes afin de participer à la diffusion de la doctrine et d'accumuler des mérites en vue de parvenir à l'Éveil. Ce faisant, il entre dans un rôle de donateur alors que le bla-ma qui enseigne le Dharma et accepte ses dons se place en chapelain. Lorsque les circonstances l'exigent, le disciple se doit de tout mettre en œuvre pour protéger le Dharma, donc le bla-ma. 
Les grandes structures monastiques qui se sont développées au Tibet n'auraient jamais pu voir le jour sans l'aide matérielle des aristocrates locaux, qui nouèrent une relation de donateur à chapelain avec le bla-ma le plus réputé de leur région. De fait, au Tibet, tout monastère a son (ou ses) protecteur(s). Le riche donateur participe à la fondation du monastère en remettant, par exemple, une partie de ses terres au bla-ma. Plus tard, il continue à verser des offrandes, en particulier lors des grandes cérémonies bouddhiques annuelles. En contrepartie, les moines du monastère exécutent des rituels, récitent des prières au bénéfice de sa famille et célèbrent les naissances et les morts qui s'y produisent.

Ainsi, dans le bouddhisme tibétain, une relation de chapelain à donateur peut s'ajouter à la classique relation de maître à disciple. Loin de se cantonner à un rôle religieux, le maître réincarné jouait aussi un important rôle politique.

Au cours de nos enquêtes dans les monastères du Tibet, et dans ceux reconstitués en Inde par la communauté tibétaine en exil, et au fil de nos recherches historiques, nous avons pu constater qu'un abbé de monastère fait peu de politique, au sens où il ne participe pas à la conduite des affaires publiques et prend rarement des initiatives dans ce domaine. Sa seule action de caractère politique consiste à accepter la requête de disciples étrangers à son monastère et désireux de recevoir un enseignement bouddhique de sa part, ce qui lui permet de voyager, de susciter des occasions d'être invité par les dirigeants politiques locaux et d'avoir des entretiens avec eux. Si les chefs politiques locaux ne se manifestent pas (ce qui est toujours possible), le maître spirituel n'en prend pas ombrage et part vers d'autres lieux, répondant à d'autres requêtes à caractère spirituel. Si un dirigeant politique saisit la perche qui lui est tendue par le dignitaire religieux et qu'il l'invite, son geste donne à celui-là l'occasion de tisser une nouvelle relation de chapelain à donateur et d'accroître la protection dont il bénéficie. Il est clair que la conduite du prélat n'est pas anodine, dans la mesure où le fait d'accepter la protection d'un dirigeant politique revient à lui fournir une sorte de certificat de bonne moralité et à cautionner sa politique. Si nous considérons que cautionner la politique d'un autre, c'est déjà faire de la politique, alors nous avons cerné le rôle d'un abbé de monastère dans ce domaine. Au fil des siècles, absorbés par leurs devoirs religieux, les dignitaires ecclésiastiques tibétains ont eu plutôt tendance à laisser leurs intendants s'impliquer dans les affaires publiques de leur région. De surcroît, peu d'entre eux se sont illustrés par des déclarations ou des prises de positions politiques fracassantes. Les faits montrent qu'ils se sont cantonnés dans un rôle politique essentiellement passif, au moins en apparence.

De nos jours, la vie des maîtres réincarnés de la Région autonome du Tibet n'a plus grand chose de commun avec la description faite ci-dessus, et notamment celles des $10^{\mathrm{e}}$ et $11^{\mathrm{e}}$ Panchen Lamas et celle du $17^{\mathrm{e}} \mathrm{Karmapa}$, dont l'influence politique est devenue primordiale. 


\subsection{L'ENJEU DE LA RECONNAISSANCE DES MAÎTRES RÉINCARNÉS}

C'est vers le $\mathrm{XII}^{\mathrm{e}}$ siècle que les bouddhistes tibétains auraient mis au point un système de recherche très perfectionné qui leur permet de retrouver la réincarnation d'un grand maître de philosophie bouddhiste décédé ${ }^{9}$. Le processus de reconnaissance d'un sprul-sku fait intervenir une série de démarches complexes. Souvent, le maître de philosophie bouddhiste donne, avant de mourir, des indications sur le lieu de naissance de sa future incarnation. Il arrive aussi que des enfants se manifestent spontanément ou qu'ils se fassent connaître par un comportement ou des pouvoirs exceptionnels. Les investigations, orientées par les prédictions des oracles et/ou par l'apparition de prodiges, sont menées secrètement par une équipe d'ecclésiastiques qui appartiennent au monastère du défunt. Les enfants susceptibles de répondre aux critères exigés sont soumis à différentes épreuves. L'une d'entre elles consiste à reconnaître un objet ayant appartenu à l'incarnation précédente présenté parmi d'autres objets anodins. Enfin, lorsqu'il ne subsiste plus aucun doute quant à l'authenticité du sprul-sku, l'enfant choisi est publiquement reconnu. Il est alors conduit à son monastère pour y être éduqué selon la tradition bouddhiste tibétaine.

Le principe de la renaissance consciente, utilisé comme règle de succession et associé à la relation de maître à disciple, a permis d'assurer la transmission ininterrompue des textes et de la doctrine. Devant l'évident avantage du principe de la renaissance consciente, d'autres ordres bouddhiques tibétains, outre celui des Karma bka'-brgyud, ont adopté ce mode de filiation. C'est le cas de l'ordre des dGe-lugs-pa auquel appartiennent les lignées des Dalaï Lamas et des Panchen Lamas. Cependant, ce principe comporte quelques inconvénients fâcheux. Tout d'abord, la complexité même des processus de recherche et de sélection laisse la porte ouverte aux contestations. Ensuite, et malgré les préparatifs méticuleux des devins et des religieux chargés de l'authentification du sprul-sku, il se peut que l'individu choisi se montre inapte à la vie à laquelle il est théoriquement prédestiné et se signale par des comportements incompatibles avec les règles en vigueur dans un monastère ${ }^{10}$. Enfin, la durée (plus de vingt ans) que le sprul-sku doit consacrer à ses études bouddhiques avant d'assumer la charge de son monastère offre à l'intendant et aux membres de son entourage, pour peu que ces derniers nourrissent quelques ambitions, bien des possibilités d'intrigue et d'assassinat ${ }^{11}$. Par ailleurs, l'enjeu politique est tel que le

9. Au Tibet, les premiers à utiliser le principe de la renaissance consciente furent, selon toute vraisemblance, les adeptes de l'ordre bouddhique des Karma bka'-brgyud. Ils auraient reconnu en Karma Pag-shi (1204-1283) la réincarnation de Dus-gsum mKhyen-pa (1110-1193), disciple de sGam-po-pa et fondateur de l'ordre. De fait, la lignée des dix-sept incarnations successives du Karma-pa rinpoche, le chef spirituel des Karma bka'-brgyud, s'etend sur plus de huit cents ans. Elle est la plus ancienne du Tibet et s'est maintenue jusqu'à nos jours.

10. Ce fut le cas du 6e Dalai Lama (1683-1707).

11. Pendant 70 ans, de 1806 à 1876 (année de naissance du $13^{\circ}$ Dalaï Lama), quatre Dalaï Lamas se succédèrent, dont pas un ne dépassa l'âge de la majorité. 
choix de l'enfant peut parfois paraître contestable ${ }^{12}$. Les Chinois qui avaient commencé par interdire la recherche des réincarnations autorisèrent l'intronisation de certaines d'entre elles à partir de $1992^{13}$.

\subsection{LES CONTROVERSES AUTOUR DE LA SÉLECTION DU PANCHEN LAMA : UN DÉBAT ANCIEN ET TOUJOURS D'ACTUALITÉ}

Les Tibétains comme les Chinois ont toujours été conscients de l'importance politique des grands maîtres réincarnés. Déjà sous les Qing (1644-1911), la dynastie mandchoue avait été confrontée à deux problèmes : d'une part, sécuriser sa frontière septentrionale contre les incursions mongoles en offrant sa protection au Dalaï Lama et au Panchem Lama, révérés eux-mêmes par les Mongols bouddhistes d'obédience dGe-lugs-pa; d'autre part, contrôler la reconnaissance des incarnations de ces deux dignitaires, alors qu'à la fin du XVIII ${ }^{e}$ siècle, les liens entre les Britanniques et le Panchen Lama s'étaient renforcés. Aujourd'hui, les deux camps tentent désespérément de s'attribuer la légitimité de leur sélection: les premiers se réclamant de la tradition, les seconds des règles édictées sous l'empire des Qing (1644-1911). Le cas du $11^{\mathrm{e}}$ Panchen Lama est, à cet égard, assez révélateur.

Le 14 mai 1995 , le $14^{\mathrm{e}}$ Dalaï Lama déclare reconnaître un enfant tibétain comme étant la réincarnation du $10^{\mathrm{e}}$ Panchen Lama (1938-1989). Ce garçon, appelé dGe-'dun chos-kyi-nyi-ma, issu d'une famille de nomades, vit dans le district de Lhari, préfecture de Nagchu au Tibet central ${ }^{14}$. Cette reconnaissance unilatérale du $11^{\mathrm{e}}$ Panchen Lama par le $14^{\mathrm{e}}$ Dalaï Lama souleva l'indignation des autorités chinoises qui s'appliquèrent à montrer que sa déclaration était «illégale » et «non avenue » (Renmin ribao, 10/5/1995). Leur principale critique étant que « le Dalaï Lama n'avait respecté ni les rites religieux traditionnels, ni les conventions historiques datant de $1792 »$ (Renmin ribao, 19, 20 et

12. Le 4e Dalaï Lama (1589-1616) était le petit-fils d'Altan-khan, protecteur mongol dont l'école dGe-lugs-pa avait besoin pour s'imposer au Tibet. Le $14^{\mathrm{e}}$ Dalaï Lama (1935-) fut trouvé dans la province de l'A-mdo au moment où cette région prenait de plus en plus d'indépendance par rapport à Lhasa. Ce choix impliquait un nouveau rattachement de l'A-mdo au gouvernement de Lhasa.

13. Le $17^{\mathrm{e}}$ Karmapa fut l'un des premiers grands maîtres réincarnés à être reconnu et intronisé par le gouvernement chinois en septembre 1992.

14. Le $14^{e}$ Dalaï Lama déclara avoir formé sa propre équipe de recherche. Ce groupe était composé de membres du monastère de bKra-shis-lhun-po du sud de l'Inde et de Tibétains vivant au Tibet central ou en exil. Les résultats des différents tests pratiqués au Tibet et en Inde permirent de sélectionner 25 enfants. Au Tibet, chacun des enfants fut soumis au test de la reconnaissance des objets ayant appartenu au $10^{e}$ Panchen Lama. Puis, le $14^{e}$ Dalaï Lama fut informé de la conclusion de ces recherches. Il accomplit alors des tests de divination par la méthode dite « des dés » à partir des photographies des différents enfants. Puis, il procéda, à plusieurs reprises, à divers exercices de divination. À chaque tentative, le nom de dGe-'dun chos-kyi-nyi-ma se serait imposé (The Observer, 21/5/1995). 
24/5/1995) ${ }^{15}$. En réalité, les autorités chinoises considéraient que « selon les rituels religieux et par convention historique, la recherche et la sélection d'un maître réincarné devaient s'effectuer sous l'autorité du gouvernement chinois, détenteur de l'autorité suprême dans le choix du maître réincarné » (Renmin ribao, 1/12/1995), d'où l'importance du tirage au sort ${ }^{16}$.

Au cours du mois de mai-juin 1995, les autorités chinoises procédèrent à de nombreuses arrestations au monastère de bKra-shis-lhun-po ${ }^{17}$ où elles firent venir une "équipe de travail" forte d'une cinquantaine de personnes qui appartenaient au Bureau des affaires religieuses, au Front uni et au Bureau de la sécurité publique. L'objectif de cette "équipe de travail" était de convaincre les moines de bKra-shis-lhun-po que seule la méthode de l'urne était légitime alors que les divinations effectuées par le $14^{\mathrm{e}}$ Dalaï Lama ne l'étaient pas. En juillet 1995, les autorités chinoises remplacèrent les membres du comité de recherche de la réincarnation du $10^{e}$ Panchen Lama et ordonnèrent la poursuite de la procédure de sélection. Le 29 novembre 1995, elles firent célébrer une cérémonie de tirage au sort qui se déroula au temple du Jo-khang à Lhasa à 2 heures du matin ! Le tirage désigna un autre enfant âgé de six ans, rGyal-mtshan nor-bu, à qui le gouvernement chinois accorda le titre de $11^{\mathrm{e}}$ Panchen Lama, alors que le nom de dGe-'dun chos-kyi-nyi-ma (l'enfant choisi par le 14' Dalaï Lama) avait été délibérément écarté de l'urne. rGyal-mtshan nor-bu fut intronisé à bKrashis-lhun-po le 8 décembre 1995 au cours d'une cérémonie télévisée. Il prononça ses vœux de moine le ler juin 1996 tandis que, dans le même temps, dGe-'dun chos-kyi-nyi-ma était assigné à résidence avec ses parents dans un lieu tenu secret. Depuis, nul ne l'a vu et ne sait s'il est toujours vivant. C'est ainsi que le Tibet possède aujourd'hui deux $11^{\mathrm{c}}$ Panchen Lama dont l'un, dGe-

15. Les autorités chinoises formèrent un autre comité de recherche de la réincarnation du $10^{\circ}$ Panchen Lama comprenant des membres du monastère de bKra-shis-lhun-po du Tibet. À la tête de ce comité, elles nommèrent Chadrel rinpoche, l'un des maîtres réincarnés de bKra-shis-lhun-po qui fut élu directeur du CGD du monastère dès 1983 et qui, en mai 1995, occupait toujours ce poste, plus celui de vice-président de la CCPPC de la Région Autonome du Tibet. Chadrel rinpoche était assisté de Jampa Chung-la, le moine secrétaire du comité de recherche et le directeur-adjoint de l'administration de la résidence du Panchen Lama de gZhis-ka-rtse. En fait, leur mission était de présélectionner, à partir des rites traditionnels, les enfants susceptibles d'être la réincarnation du $10^{e}$ Panchen Lama. Ils devaient ensuite informer le gouvernement chinois de leurs résultats. Il semble aussi qu'ils étaient en communication avec le $14^{\mathrm{e}}$ Dalaï Lama (Rapport d'Amnesty International, 27/5/1997). Enfin, conformément à l'édit impérial de 1792, à partir de leur présélection, les autorités chinoises voulaient procéder à un tirage au sort qui aurait déterminé leur choix (Renmin ribao, 26/8/1989).

16. D'après l'édit du 1792, une fois les premiers tests effectués par les maîtres tibétains conformément aux rites traditionnels, les noms des enfants sélectionnés doivent être inscrits sur des bâtonnets d'ivoire et déposés dans une urne en or. Le Dalaï Lama (ou le régent si le Dalaï Lama n'est pas vivant ou en âge de gouverner, ou le Panchen Lama) selon le cas et l'agent impérial mandchou (aujourd'hui le représentant du gouvernement chinois) participent à l'épreuve du tirage au sort. Ce tirage s'effectue devant une statue de Tsong-kha-pa dans le temple du Jo-khang à Lhasa.

17. Le 17 mai 1995, Chadrel rinpoche et son assistant Jampa Chung-la sont arrêtés : ils nc scront jugés que le 21 avril 1997 et condamnés à de lourdes peines de prison (respectivement six ans et quatre ans) pour avoir « conspiré pour diviser le pays» et pour « avoir divulgué des secrets d'État » (Tibet Information Network, 1996, p. 52). 
'dun chos-kyi-nyi-ma, est devenu le plus jeune prisonnier politique du monde (qui, à ce titre, suscite l'inquiétude de l'opinion publique internationale) et l'autre, rGyal-mtshan nor-bu, est ignoré par le peuple tibétain au point que les autorités chinoises préfèrent le garder à Pékin. Cette situation ubuesque n'est que la conséquence d'une large implication du monde politique dans les institutions religieuses. Elle trouve son origine dès la première moitié $\mathrm{du} \mathrm{xx}^{\mathrm{e}}$ siècle, lors de la reconnaissance du $10^{\mathrm{e}}$ Panchen Lama, qui, toute sa vie durant, a subi de fortes pressions politiques.

Le choix de l'un ou l'autre de ces enfants comme étant le $11^{\mathrm{e}}$ Panchen Lama ne change rien au problème de sa légitimité. En effet, chacune des deux parties semble avoir oublié que la sélection du $10^{\mathrm{e}}$ Panchen Lama (1938-1989), son prédécesseur, ne fut conforme ni aux règles traditionnelles tibétaines, ni à l'édit de 1792.

Le gouvernement nationaliste qui venait de perdre le $9^{\mathrm{e}}$ Panchen Lama (1883-1937), avec lequel il espérait reprendre pied au Tibet, comptait garder sa réincarnation sur le territoire chinois et l'utiliser le moment venu. C'est pourquoi il s'empressa de reconnaître l'enfant choisi par les fonctionnaires de bKrashis-lhun-po, aidés de ceux du gouvernement tibétain, ainsi que les membres de la suite du $9^{e}$ Panchen Lama qui étaient restés au monastère de $s \mathrm{Ku}$-'bum, à Xining au Qinghai (Jiangbian, 1989, pp. 3-8; Renmin ribao, 5/2/1989). De son côté, en 1944, le gouvernement tibétain découvrit deux autres candidats et demanda alors que les trois candidats soient amenés à bKra-shis-lhun-po afin d'y subir les tests religieux traditionnels qui les départageraient. Les Chinois refusèrent. Par conséquent, le candidat de Xining fut installé au monastère de sKu-'bum afin d'y recevoir son éducation religieuse (il y sera intronisé le 10 août 1949) et les deux candidats du gouvernement tibétain entrèrent, l'un au monastère de 'Bras-spungs, l'autre à celui de bKra-shis-lhun-po dans le même but. Le gouvernement chinois reconnut officiellement l'enfant de Xining comme étant le $10^{\mathrm{e}}$ Panchen Lama le 3 juin 1949 sans tenir compte de l'avis tibétain (Shakabpa, 1988, p. 306). Mais, pour les Tibétains, la question n'était pas tranchée.

La proclamation de la République populaire de Chine, le $1^{\text {er }}$ octobre 1949 , avec Mao Zedong comme président ne changea rien à l'affaire. La République populaire de Chine réussit là où la Chine nationaliste avait échoué : le 28 avril 1952, le $10^{\mathrm{e}}$ Panchen Lama entra au Tibet escorté des troupes chinoises (Dhondup, 1978, p. 13) et fut intronisé dans son monastère le 6 juin 1952 (Jiangbian, 1989, p. 34-35). Cette question de légitimité met en évidence la faiblesse du principe de réincarnation que chacune des parties exploite à sa manière. Dans le cas de la reconnaissance du $11^{\mathrm{e}}$ Panchen Lama, le gouvernement tibétain en exil et le gouvernement chinois jouaient une course contre la montre. Pour le $14^{\mathrm{e}}$ Dalai Lama, il était important de reconnaître publiquement le $11^{\mathrm{e}}$ Panchen Lama avant les Chinois afin de réaffirmer sa suprématie sur les affaires religieuses tibétaines et surtout sur des rites religieux que lui seul est habilité à célébrer pour le Panchen Lama. Pour les Chinois, dans le cas du $11^{\mathrm{e}}$ Panchen 
Lama, il s'agissait de montrer au monde qu'ils contrôlaient le Tibet. Et à long terme, ils pouvaient modeler et manipuler un maître dont l'aura spirituelle est reconnue par tous les Tibétains en vue de lui attribuer un rôle politique équivalent à celui dévolu au $10^{e}$ Panchen Lama.

Les Chinois cherchèrent d'abord à montrer que le $14^{\mathrm{e}}$ Dalaï Lama et le $10^{e}$ Panchen Lama étaient de rang égal et qu'ils exerçaient tous les deux un pouvoir politique. Ainsi, lorsqu'en 1951, ils divisèrent le Tibet en trois régions, ils répartirent aussi les pouvoirs : le district de Chab-mdo était désormais dirigé par le «Comité de libération du peuple de la région de Chab-mdo »; le district de gZhis-ka-rtse par le $10^{\mathrm{e}}$ Panchen Lama et son conseil et le Tibet Central par le $14^{\mathrm{e}}$ Dalaï Lama et son gouvernement. En 1954 , le $14^{\mathrm{e}}$ Dalaï Lama et le $10^{\mathrm{e}}$ Panchen Lama furent invités à assister à la première Assemblée nationale populaire. Le 27 avril 1956, lors de l'inauguration de la Commission préparatoire pour la création de la Région autonome du Tibet, le $14^{\mathrm{e}}$ Dalaï Lama devint son président, le $10^{\mathrm{e}}$ Panchen Lama son vice-président, le général chinois Zhang Guohua son second vice-président et Ngag-phod Ngag-dbang 'Jigs-med son secrétaire général (Dhondup, 1978, p. 13).

Après la fuite du $14^{\mathrm{e}}$ Dalaï Lama le 10 mars 1959 , la dissolution du gouvernement tibétain fut prononcée et le $10^{\mathrm{e}}$ Panchen Lama occupa pleinement le devant de la scène politique. Il fut nommé président par intérim de la « Commission préparatoire pour la création de la Région autonome du Tibet », le $14^{\mathrm{e}}$ Dalaï Lama gardant le titre de président (Renmin ribao, 5/2/1989; Jiangbian, p. 73). Le $10^{\mathrm{e}}$ Panchen Lama se désolidarisa du $14^{\mathrm{e}}$ Dalaï Lama et assista à la deuxième Assemblée nationale populaire à Pékin (Jiangbian, 1989, p. 74). Il était devenu l'interlocuteur privilégié pour ce qui était des affaires tibétaines au sein du gouvernement chinois.

Puis, l'attitude du $10^{e}$ Panchen Lama changea radicalement après que l'Armée populaire de libération s'en fut pris à son monastère et que ses moines furent arrêtés ou sécularisés à la fin de l'année 1960 (Jiangbian, 1989, p. 81). Le prélat protesta auprès du Parti communiste chinois et prit la défense, pour la première fois, du $14^{\mathrm{e}}$ Dalaï Lama. Le point culminant de sa rébellion fut la rédaction du texte connu sous le nom de « Rapport en 70000 caractères » qu'il rédigea après avoir entrepris une tourné d'inspection au Sichuan et au Qinghai en 1962. Il y critiquait la politique appliquée par les Chinois au Tibet et fit la prédiction que leur maintien pourrait entraîner la disparition des Tibétains et de leur religion. Deux ans plus tard, il soutint ouvertement le $14^{\mathrm{e}}$ Dalaï Lama et se prononça en faveur de l'indépendance du Tibet. Du 18 septembre au 4 novembre 1964, il fut violemment critiqué pour ses prises de position alors qu'il participait au $7^{e}$ congrès de la «Commission préparatoire pour la création de la Région autonome du Tibet ». Il fut démis de ses fonctions de président par intérim de la Commission (Jiangbian, 1989, p. 148). À la fin de l'année 1964, il quitta Lhasa pour Pékin où il resta emprisonné plus de treize ans.

La révolution culturelle terminée, le gouvernement chinois lui attribua de nouveau des titres officiels : il devint député à l'Assemblée nationale populaire 
en 1978, puis vice-président de l'Assemblée nationale populaire en 1980. Le gouvernement chinois l'autorisa enfin à retourner au Tibet en 1982, puis en 1986. Ses deux voyages révélèrent combien il était vénéré par la population tibétaine. L'influence du $10^{\mathrm{e}}$ Panchen Lama étant toujours aussi grande, le gouvernement chinois décida de lui accorder un nouveau rôle après les premières émeutes nationalistes qui éclatèrent à Lhasa le 27 septembre et le ler octobre 1987 : celui de stabilisateur et de modérateur. Le prélat se rendit alors au Tibet dans le but d'examiner la situation sur place (Renmin ribao, 6/2/1988). En dépit de cela, de nouvelles manifestations éclatèrent à Lhasa en mars 1988. Peu après, le 4 avril, Nga-phod Ngag-dbang 'Jigs-med condamna violemment l'attitude des Tibétains tandis que le $10^{\mathrm{e}}$ Panchen Lama évitait d'accuser le $14^{\mathrm{e}}$ Dalaï Lama d'être à l'origine des troubles. En fait, le $10^{e}$ Panchen Lama était devenu l'indispensable médiateur entre les Tibétains et le Parti communiste chinois. À ce titre, le lendemain, il fut officiellement réhabilité.

Cependant, à partir de 1988 , le $10^{\mathrm{e}}$ Panchen Lama se fit plus actif. Il chercha à rétablir l'usage de la langue tibétaine dans l'administration et il ouvrit des instituts bouddhiques. Surtout, il dénonça l'absurdité de certaines des politiques conduites au Tibet. En janvier 1989, il se rendit au monastère de bKra-shislhun-po dans le but d'inaugurer un stupa rénové rassemblant les dépouilles des $2^{\mathrm{e}}$ au $5^{\mathrm{e}}$ Panchen Lamas. Il y prononça un discours très incisif envers le Parti communiste chinois (AFP, 25/1/1988), puis mourut brutalement le 28 janvier (officiellement d'une crise cardiaque). Le 31, le Parti communiste chinois autorisa la recherche de sa réincarnation, mais stipula qu'elle ne pourrait se dérouler qu'en Chine (Renmin ribao, 26/8/1989). Les Tibétains et les Chinois venaient de perdre leur seul dénominateur commun.

\subsection{LES AUTRES GRANDS MAÎTRES RÉINCARNÉS : LE KARMAPA}

Il fallut quatre années d'attente aux uns et aux autres avant qu'ils ne retrouvent un nouveau motif d'espoir de négociation, en la personne du jeune ' $O$ rgyan-'phrin-las-rdo-rje qui, le 27 septembre 1992, reçut à l'âge de six ans le titre de $17^{\mathrm{e}}$ Karmapa en son monastère de mTshur-phu (situé à $60 \mathrm{~km}$ de Lhasa). Car, contrairement à ce qui se passera ultérieurement dans le cas du $11^{\mathrm{e}}$ Panchen Lama, chose exceptionnelle, le $17^{\mathrm{e}}$ Karmapa fut reconnu à la fois par le $14^{\mathrm{e}}$ Dalai Lama et par les autorités chinoises. Il constituait donc une carte maîtresse dans le jeu du gouvernement de Pékin qui choyait son enfance avant de pouvoir l'utiliser dans le processus de normalisation du Tibet. Cependant, le $17^{\mathrm{e}}$ Karmapa surprit le monde entier en s'échappant de son monastère le 28 décembre 1999 pour rejoindre le 14 Dalaï Lama en Inde le 5 janvier 2000. Sa fuite provoqua l'emprisonnement de ses parents et un durcissement du contrôle chinois dans l'ensemble de la Région autonome du Tibet. Elle causa aussi l'embarras des Chinois qui se seraient passés d'une telle publicité. Elle constitue pour eux un deuxième revers puisque, dès 1998, A-kya'a rinpoche, l'abbé du monastère de sKu-'bum, s'était enfui aux États-Unis où il a obtenu l'asile politique. Avant sa fuite, en plus de son titre d'abbé de sKu-'bum, A-kya'a rin- 
poche était membre de la CCPPC, vice-président de la Conférence consultative politique du peuple du Qinghai, vice-président de l'Association bouddhiste chinoise et président de l'Association bouddhiste du Qinghai. Il déclara s'être échappé car sa position était devenue intenable après qu'il eut soutenu le choix du $14^{\mathrm{e}}$ Dalaï Lama concernant le $11^{\mathrm{e}}$ Panchen Lama. Après l'annonce du $14^{\mathrm{e}}$ Dalaï Lama, lorsque Chadrel rinpoche (cf. notes 15 et 17) fut emprisonné, les autorités chinoises exigèrent d'A-kya'a rinpoche qu'il critique publiquement ce dernier et qu'il participe à la cérémonie du tirage au sort du 29 novembre 1995, ce qu'il fit sous la contrainte. Il devint ensuite l'objet de brimades répétées jusqu'à être forcé de mettre en place, en 1998, un cours de formation politique dans son monastère et de dénoncer publiquement les activités du $14^{\mathrm{e}}$ Dalaï Lama. C'est alors qu'il décida de s'échapper (discours du 16/3/2000). Les autorités chinoises mirent du temps à reconnaître la défection d'A-kya'a rinpoche puisqu'il n'a été officiellement limogé de son poste au sein de la Conférence consultative politique du peuple chinois que le 23 juin 2000 et qu'il n'a toujours pas été déchu de son titre de vice-président de l'Association bouddhiste chinoise (AFP, 28/6/2000).

Ainsi, l'histoire du $10^{\mathrm{e}}$ Panchen Lama, celle du $11^{\mathrm{e}}$ Panchen Lama, celle du $17^{\mathrm{e}}$ Karmapa et celle d'A-kya'a rinpoche enseignent qu'au Tibet d'aujourd'hui, les rôles religieux et politiques des maîtres réincarnés n'ont plus rien à voir avec ce qu'ils furent dans le passé. Ces personnages exercent une activité religieuse rigoureusement encadrée par le gouvernement chinois, comportant un nombre d'enseignements et d'initiations bouddhiques très inférieur à celui d'avant 1959. Quant à leurs activités politiques, comparées au passé, elles paraissent florissantes si nous nous fions aux titres ronflants qui ornent leurs cartes de visite. En réalité, l'expérience du $10^{\circ}$ Panchen Lama et d'A-kya'a rinpoche montrent que leur marge de manœuvre est assez faible et qu'ils ont été le plus souvent cantonnés à des rôles honorifiques, payant de la prison ou de l'exil l'expression de leurs convictions. Les départs successifs du $17^{\mathrm{e}}$ Karmapa et d'A-kya'a rinpoche montrent que le gouvernement chinois exerce une pression politique trop forte sur le religieux. Sinon, en toute logique, ceux-ci n'auraient pas quitté le Tibet.

\section{CONCLUSION}

Il est toujours difficile de se faire une opinion objective sur la situation qui prévaut aujourd'hui au Tibet et sur le poids que la politique exerce sur le religieux, à l'intérieur comme à l'extérieur, tant le sujet reste sensible. La duplicité évidente du gouvernement chinois à cet égard et l'aveuglement doublé de parti pris de certains journalistes occidentaux, qui imposent à l'opinion internationale leur vision romantique d'un Tibet qui n'a jamais existé ailleurs que dans leur imagination fertile, ne facilitent pas la tâche des observateurs.

La polémique qui oppose toujours les autorités de Pékin et le $14^{\mathrm{e}}$ Dalaï Lama au sujet de la sélection du $11^{\mathrm{e}}$ Panchen Lama est à observer avec attention. Elle 
est très représentative du niveau actuel d'interaction du politique et du religieux au Tibet. En outre, elle recèle probablement la clef de la résolution du très complexe problème sino-tibétain. Depuis sa fuite du Tibet, le $14^{\mathrm{e}}$ Dalaï Lama et son gouvernement en exil véhiculent l'idée que la religion tibétaine est unique, qu'elle unit tous les Tibétains et qu'à ce titre elle doit être préservée. En réalité, elle est devenue un ferment du nationalisme tibétain en exil et au Tibet comme en témoignent les manifestations indépendantistes qui se déroulèrent à Lhasa de 1987 à 1989 (les manifestants étaient tous des moines ou des moniales et les manifestations débutèrent toutes sur les lieux sacrés de Lhasa). Ce "bouddhisme nationaliste", associé à l'idée d'exploitation des masses par les religieux qui prévalait dans les années cinquante et soixante, explique la pression politique considérable exercée sur la religion tibétaine par les Chinois. Depuis récemment, les Chinois non seulement limitent les ordinations et les restaurations de monastère mais cherchent aussi à démontrer que le bouddhisme n'est pas la religion originelle du Tibet, mais une religion importée de l'Inde, et qu'en revanche, la tradition bön l'est. À ce titre, ils encouragent cette dernière religion à se développer (à travers le financement de l'édition du canon bönpo, par exemple).

Cette question pourrait mettre en péril le fragile équilibre nationaliste bâti en exil. En effet, dès le début des années soixante, le $14^{\mathrm{e}}$ Dalaï Lama et le gouvernement en exil ont dû trouver un moyen d'unir sous une même bannière les Tibétains réfugiés issus des trois régions tibétaines (création d'un hymne national, d'un drapeau, par exemple). Ils ont choisi le bouddhisme. Or la religion aborigène bön, dont les pratiquants ont toujours été rejetés du Tibet central vers les régions périphériques tibétaines - le Khams et l'A-mdo - s'est surtout étendue dans ces régions où le sentiment autochtone est très fort. Les habitants de ces deux provinces tibétaines pourraient facilement décider d'affirmer leur identité (en utilisant le bön comme point de ralliement) et se désolidariser du Tibet central, et donc de la politique menée par le $14^{\mathrm{e}}$ Dalaï Lama et son gouvernement, que ce soit au Tibet ou en Inde. 


\section{BIBLIOGRAPHIE}

Barnett R. \& Akiner S., Eds. (1994), Resistance and Reform in Tibet, London : Hurst.

Bell C. (1968), Tibet: Past and Present, Oxford : Oxford University Press (1ère édition, 1924).

Bell C. (1987), Portrait of a Dalai Lama: The Life and Times of the Great Thirteenth, London: Wisdom (1ère édition, 1946).

Carrasco P. (1959), Land and Polity in Tibet, Seattle: University of Washington Press.

Dhondup K. (1978), "Panchen Lama, the Enigmatic Tibetan", Tibetan Review, FebruaryMarch, pp. 13-17.

Goldstein M. (1986), "Reexamining Choice, Dependency and Command in the Tibetan Social System: Tax Appendages and Other Landless Serfs", The Tibet Journal, Vol. 11, no 4, pp. 79-112.

GoldsteIn M. (1989), A History of Modern Tibet, 1913-1951, The Demise of the Lamaist State, Berkeley : University of California Press, 2 vol.

GoldsteIn M. \& KAPSTEIN M. (1988), Buddhism in Contemporary Tibet. Religious Revival and Cultural Identity, Berkeley: University of California Press.

Goldstein M., Siebenschun W. \& Tsering T. (1997), The Struggle for Modern Tibet, The Autobiography of Tashi Tsering, Armonk : M.E. Sharpe.

JiAngBIAN J. (1989), Banchan dashi (Le Grand maître Panchen), Beijing : Dongfang chubanshe.

MENGzI, compilateur (1993), The Hidden Tradition. Life Inside the Great Tibetan Monastery. Tashilhunpo, Beijing : Foreign Languages Press.

Samuel G. (1993), Civilized Shamans, Buddhism in Tibetan Societies, Washington : Smithsonian Collection.

ShakabPa T. W. (1988), Tibet: A Political History, New York : Potala (1ère édition, 1967).

SHAKYA T. (1989), Religious Freedom in Tibet, Unpublished paper.

SHAKYA T. (1999), The Dragon in the Land of Snows. A History of Modern Tibet since 1947, London : Pimlico.

Surkhang W. G. (1986), "Government, Monastic and Private Taxation in Tibet", The Tibet Journal, Vol. 11, no 1, pp. 21-40.

Tibet INFORMATION NetworkJHuman Rights Watch, Cutting Off the Serpent's Head. Tightening Control in Tibet, 1994-1995.

Van Walt van PraAg M. C. (1987), The Status of Tibet, History, Rights and Prospects in International Law, London: Wisdom. 